\title{
Dynamic Stability Analysis of Slope Subjected to Surcharge Load considering Tensile Strength Cut-Off
}

\author{
Guangdong Lv $D^{1},{ }^{1} \mathrm{Yi} \mathrm{He}^{2}$ and Bingsi $\mathrm{Wei}^{3}$ \\ ${ }^{1}$ Water Conservancy Project \& Civil Engineering College, Tibet Agriculture \& Animal Husbandry University, \\ Nyingchi 860000, China \\ ${ }^{2}$ Sichuan Southwestern Construction Engineering Technology Co., Ltd., Chengdu 610081, China \\ ${ }^{3}$ Nanning Exploration \& Survey Geoinformation Institute, Nanning 530021, China \\ Correspondence should be addressed to Guangdong Lv; guangdonglv@xza.edu.cn
}

Received 30 March 2020; Revised 23 July 2020; Accepted 3 August 2020; Published 13 October 2020

Academic Editor: Francesco Cannizzaro

Copyright (c) 2020 Guangdong Lv et al. This is an open access article distributed under the Creative Commons Attribution License, which permits unrestricted use, distribution, and reproduction in any medium, provided the original work is properly cited.

\begin{abstract}
Surcharge slopes are more vulnerable to instability under the effects of earthquake ground shaking, especially considering the tensile stress. In order to account for the adverse factors of seismic forces and tensile stress, the theory of soil with tensile strength cut-off is deduced and analyzed using the upper bound limit analysis method in this paper. Combined with the quasistatic analysis, the equation of critical acceleration expression for surcharge slope subjected to the dynamic conditions has been evaluated. By using the improved Newmark method, permanent displacements have been analyzed in the case of the classical earthquake ground motions. In addition, optimization algorithm has been undertaken, in which several influencing factors such as slope inclination, internal friction angle, surcharge factor, seismic load, and tension cut-off coefficient have been taken into account, and some results are verified with the classical solutions and FEM results. The results concluded the following: (1) The outcomes of verification results are accurate. (2) The critical acceleration of the slope is significantly affected by tension cut-off with the increasing of surcharge factor and seismic effects. (3) The permanent displacements of surcharge slope considering the tensile strength cut-off can be even 2 times of the traditional analysis; meanwhile, with more reduction of tensile strength, the cumulative displacements increase rapidly. Therefore, considering the influence of tensile strength cut-off is fundamental to the dynamic stability design of surcharge conditions.
\end{abstract}

\section{Introduction}

Earthquake is one of the most destructive geological disasters in nature. When an earthquake occurs, it has a tendency to induce secondary disasters such as landslides and rockfalls, creating a chain of disasters, which threatens social economy and human lives; therefore, many scholars have been studying and analyzing the seismic slope stability consistently. Terzaghi proposed a quasistatic method to analyze the stability of slope subjected to the seismic loading conditions [1]. Because of its simplicity and convenience, it has become mainstream conventional method among today's engineers. However, the quasistatic method ignores the dynamic process of the earthquake, which cannot effectively reflect the permanent displacement of the slope. In 1965,
Newmark proposed a method to calculate the sliding displacement of slope under dynamic condition [2] and obtained the critical acceleration and the analysis of permanent displacement theory to effectively analyze the stability of slope subjected to the seismic conditions. However, the essence of Newmark method is a rigid sliding block approach, which ignores the influence of slope internal deformation, due to which there is a continuous research work going on to improve the method $[3,4]$.

Currently, the linear Mohr-Coulomb yield criterion (hereinafter referred to as $\mathrm{M}-\mathrm{C}$ criterion) has been usually used to evaluate the stability of slope, while there are a few researches of nonlinear strength characteristics of rock and soil, and nonlinear characteristics tend to show more adverse damage on slope stability. The results of geotechnical 
tests show that utilizing the shear strength, which obeys the linear shear strength envelope, considering properties like cohesion $c$ and internal friction angle $\varphi$, the factual tensile strength cannot be obtained [5]. On the other hand, two methods are usually considered for evaluating the landslide [6]. One of the effective ways to evaluate the slope is to reduce the tensile strength of rock and soil to some extent, that is, to optimize the linear failure curve to the nonlinear strength envelope; the other method is to introduce different kinds of tensile cracks. For the latter method, Michalowski [7] and Park and Michalowski [8] studied the slope overall sliding state combined with the crack propagation. The results showed that the existence of cracks significantly increases the risk of instability for high-steep slopes or slopes significantly affected by hydrostatic pressure. Li et al. [9] developed a framework to make the static and seismic stability evaluation of slopes with cracks based on the kinematic upper bound limit analysis. Results show that, when considering the existence of cracks, it leads to a significant reduction in safety factor of slope, whereas the inclusion of $3 \mathrm{D}$ effects yields a greater safety factor. Jamalinia et al. [10] integrated the method of a crop model and a Finite Element Method (FEM) model to add the impact of cracking building on a previous study. Results simulating a ten-year period indicate a strong impact of cracking on the factor of safety. For the former method, the current method is mostly based on the variational method or limit analysis method. Park et al. [11] studied the influence of the tensile strength variation on the slope stability and fracture morphology, based on the upper bound limit analysis, and optimized the strength envelope in the classical $\mathrm{M}-\mathrm{C}$ criterion with circular-arc curve. He et al. [12] discussed the safety factor and permanent displacement of slope with the tensile strength cut-off under seismic load; the research combined with the quasistatic method and the Newmark slider method and results showed that, for vertical slopes subjected to seismic loads, the safety factor is reduced by $55 \%$, and the slope displacement caused by the earthquake is approximately twice that obtained with the consideration of Mohr-Coulomb (M-C) yield criterion. The upper bound limit analysis method does not need to consider the stress in the initial state of soil, and it is easy to obtain clear mechanical concept in calculation; hence, it has gradually become a research hotspot in slope field in the recent years, especially combined with the tensile strength cut-off, which is also exactly what this paper discusses.

In practice, slope subjected to surcharge is a common problem, and the damage is more serious when the landslide occurs. Surcharge has a disadvantage effect on slope, which increases the sliding force and decreases the stability against sliding. If the surcharge is in the form of constructions or man-made works, it will even cause unpredictable losses. Nowadays, there is no relevant study on the full-range dynamic analysis of surcharge slope considering the tensile strength reduction of soil. As compared to previous studies, this paper studies the critical failure morphology of surcharge slope and deduces critical functional equation via the limit analysis upper bound method; and then it optimizes algorithm further and combines the random search method and the quadratic optimization method [13] to solve the problem. Finally, the research selected measured ground motions to analyze the influence of various surcharge factors and tension cut-off factors on slope stability, according to the case of slope failure in the earthquake.

\section{The Strength Envelope of Soil}

When analyzing the stability of slopes, the soil is generally considered as an ideal homogeneous material; that is, it shows sliding or yielding when reaching the limit stress. The tensile strength of soil is mainly obtained by extrapolation from the compression state measured by experiments, which is not a true value. Therefore, $\mathrm{M}-\mathrm{C}$ criterion cannot accurately reflect the tensile strength, which affects the evaluation results of slope stability. In addition, many experimental results show that the nonlinear strength failure envelope can more approximately reflect the tensile strength of rock and soil.

In principal stress space, the classical M-C criterion can be expressed as a cone with irregular hexagon as shown in Figure 1(a). When solid particles are chemically bonded (as in rock), cohesion is represented through uniaxial compressive strength and uniaxial tensile strength. The apex of the pyramid represents the triaxial tensile strength (isotropic), while the points of principal stress axis and yield surface represent uniaxial compressive strength and uniaxial tensile strength. Paul [14] modified the classical M-C yield surface to limit the tensile strength as shown in Figure 1(b). The tensile strength $f_{\mathrm{t}}$ after cutting-off can be expressed as stress circle $C_{1}$ as shown in Figure 2(a). The transformation from the Mohr circle (Figure 2) to the principal stress space (Figure 1) is a complex process, the stress state on the $\mathrm{AB}$ side of the section $A B C D E F$ (Figure 1(b)) is represented by the stress circle $C_{2}$ (Figure 2(b)), and each position on $\mathrm{AB}$ is determined by the principal stress $\left(\sigma_{1} \geq \sigma_{2} \geq \sigma_{3}\right)$. For example, stress circle $C_{1}$ (Figure 2) when $\sigma_{2}=0$ corresponds to the intersection of $\mathrm{ABCDEF}$ section and $\sigma_{3}$ axis in (Figure 1(b)), while Point $\mathrm{P}$ (Figures 1 and (2b)) corresponds to the stress state of corner $C$ (Figure 1(b)). The yield surface in the limit state is mapped from the smooth yield surface (Figure 2) to the yield surface with edges and corners (Figure 1). The cut-off tensile stress zone method is suitable for the analytical kinematic method in limit analysis. However, as the normal vector is not unique at the corner of the yield surface in principal stress space, its applicability in the numerical method needs further study.

The traditional M-C strength envelope is shown in Figure 2(a); the M-C function is a simple combination of straight line and circular arc. In M-C calculation, the triaxial tensile strength is $f_{3 t}=c / \tan \varphi$, while the uniaxial tensile strength is $f_{t}=2 c \cos \varphi /(1+\sin \varphi)$. When considering the tensile strength cut-off, the drag vector changes from straight line to arc, and dilatancy angle $\delta$ in tensile stress zone changes from $\varphi$ to $\pi / 2$; it becomes M-C linearity yield criterion when $\delta=\varphi$. In order to show tensile strength cutoff quantitatively, this paper introduces the reduction coefficient $\xi$, which can be expressed as 


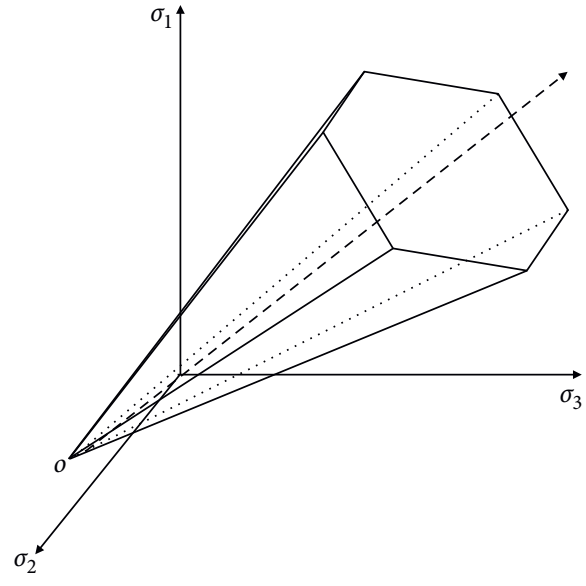

(a)

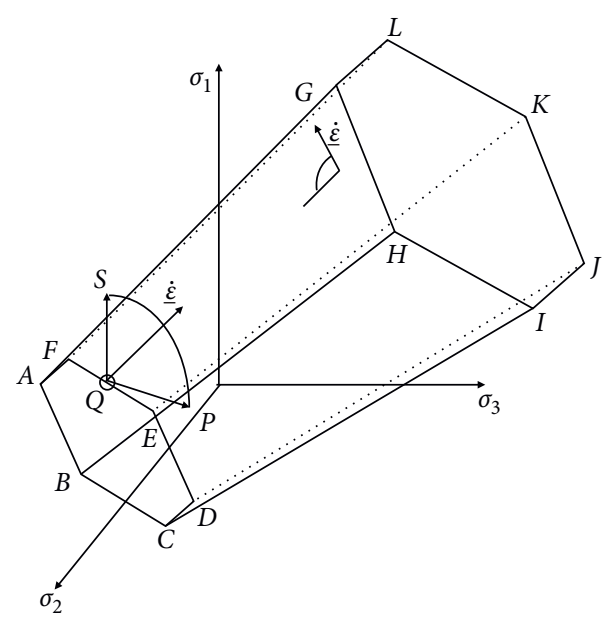

(b)

Figure 1: (a) The classical M-C criteria. (b) Tension cut-off model of soils.

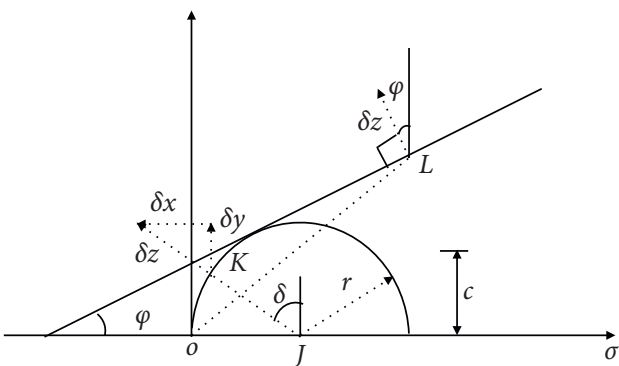

(a)

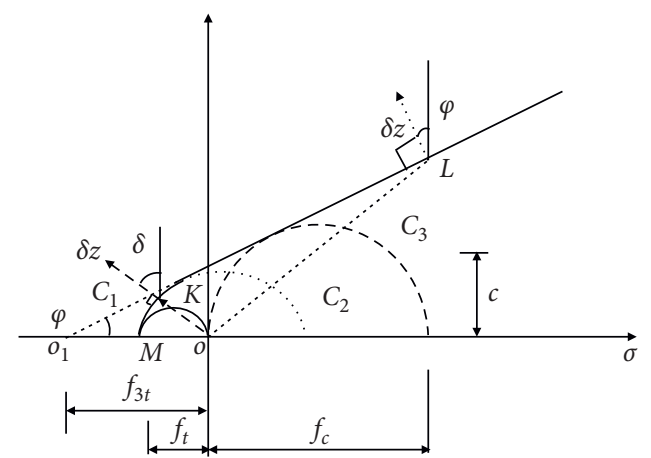

(b)

Figure 2: (a) The classical M-C envelope. (b) Tension cut-off envelope of soils.

$$
f_{t}^{\prime}=\xi f_{t}=\xi \frac{2 c \cos \varphi}{1+\sin \varphi}
$$

where $\xi=0-1$; when $\xi=1, f_{t}^{\prime}$ is the tensile strength under the linear M-C criterion; when $\xi=0$, it indicates the failure state where the tensile strength is not considered at all, as shown in Figure 2(b). The analytical kinematic process of limit analysis is greatly simplified by using this method. Accordingly, Tierney [15] deduced equation of tensile strength unit energy dissipation:

$$
d_{c}=\left(f_{c} \frac{1-\sin \delta}{2}+\xi f_{t} \frac{\sin \delta-\sin \varphi}{1-\sin \varphi}\right)[v],
$$

where $f_{\mathrm{c}}$ is uniaxial compressive strength; $f_{\mathrm{c}}=2 c \cos \varphi /$ $(1-\sin \varphi)$.

\section{Failure Mechanism and Calculating Analysis}

3.1. Failure Mechanism. Based on the kinematic theory of slope stability, Qin et al. [16, 17] adopted a new perspective with a discretisation technique and pseudodynamic approach. The research selected infinitesimal trapezoidal elements composed of successive discretised points and sloping surface for kinematic analysis. Zheng et al. [18] proposed a modified graphical approach and the differences of the intersection angle between the slope impact and the discontinuous point, cut slope dip angles, and discontinuity friction angles of the discontinuous point under different extreme conditions are studied. In this research, the logarithmic spiral model of tensile shear failure mechanism [19] is used to represent the sliding surface of slope. Figure 3 shows the critical homogeneous surcharged slope model under seismic loads, where $\beta$ is the angle of slope, $H$ is the height of intact failure slope, and $H^{\prime}$ is the local height of face failure slope. This research assumes that the failure mechanisms may in principle occur on the slope face above the slope toe (a local failure). Therefore, the potential failure mechanisms passing above the toe were taken into account in the analysis and in calculating the stability factor associated with each potential mechanism (Figure 3(a)). The local failure mechanism has a similar shape to that of the intact toe-failure mechanism but a smaller height $H^{\prime}$. In other words, the toe-failure mechanism is a special case of 


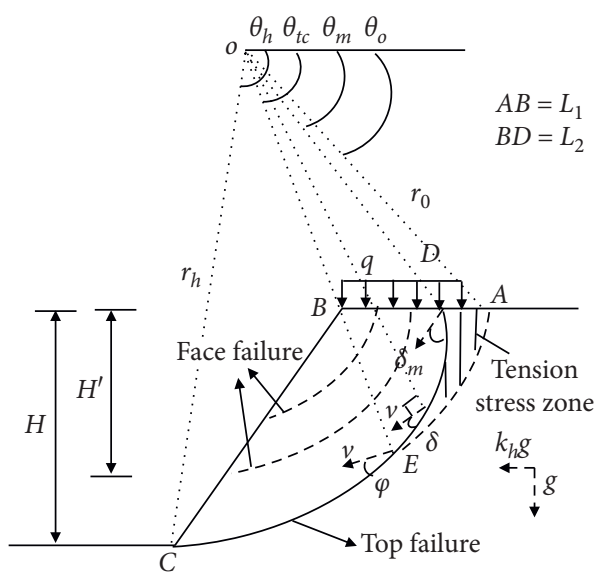

(a)

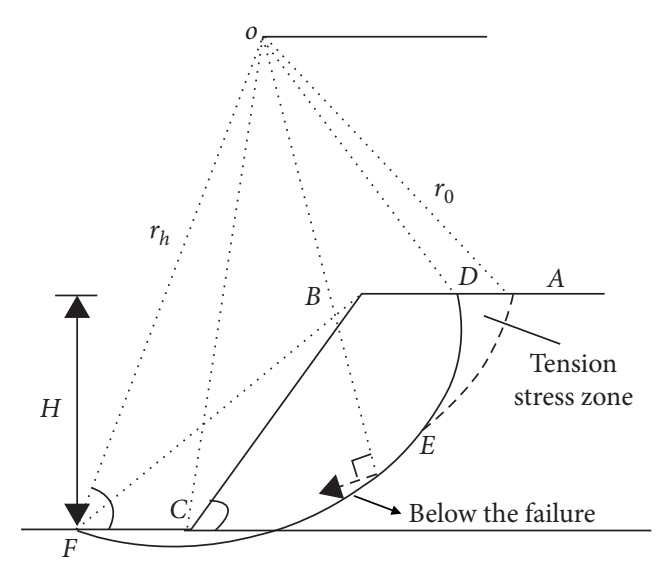

(b)

FIGURE 3: Instability mechanism of slope considering tension cut-off.

the face failure mechanism when $H=H^{\prime}$. However, in all the cases considered in this study, no potential mechanism passing in the slope face turned out to be a failure mechanism. Other parameters are internal friction angle $\varphi$, cohesion $c$, and bulk density $\gamma$. The different failure mechanisms of the slope are shown in Figure 3, when the whole damage is toe failure, and the block BDEC rotates along the slip surface DEC with point $O$ as the circle center, where DEC is critical sliding surface. It is found that the tensile stress is more likely to occur on the top of the slope nearby. The DE curve of the sliding surface is caused by tension cut-off, and the lower curve (EC) is caused by the linear envelope. Dilatancy angle of DE curve decreases from the maximum value $\delta_{\max }$ at point $D$ to $\varphi$ at point $E$. Figure 4 shows a micro element on the DE curve; it can be seen that

$$
\begin{gathered}
\mathrm{d} r=r \tan \delta(\theta) \mathrm{d} \theta, \\
\int_{r_{m}}^{r} \frac{\mathrm{d} r}{r}=\int_{\theta_{m}}^{\theta} \tan \delta(\theta) \mathrm{d} \theta .
\end{gathered}
$$

The integral along DE can be obtained as follows:

$$
r=r_{0} e^{\left(\theta_{m}-\theta_{0}\right) \tan \varphi} e^{\int_{\theta_{m}}^{\theta} \tan \delta(\theta) \mathrm{d} \theta}
$$

where $r_{0}$ is the distance $\mathrm{AO}$ from the starting point $\mathrm{A}$ of the logarithmic helix to the radius of the rotation; $\theta_{0}$ is the angle between $\mathrm{AO}$ and the horizontal line (as shown in Figure 2); $\theta_{h}$ is the angle between the radius from the ending point of the logarithmic helix to the rotation center and the horizontal line; $\theta_{m}$ is the angle between OD and horizontal line, and $\theta_{t c}$ is the angle between $\mathrm{OE}$ and horizontal line; $\delta$ is dilatancy angle, and it can be expressed as follows:

$$
\delta(\theta)=\delta_{m}-\frac{\delta_{m}-\varphi}{\theta_{t c}-\theta_{m}}\left(\theta-\theta_{m}\right) .
$$

The limit analysis upper bound method is based on the balance of energy dissipation rate inside and outside the block as follows:

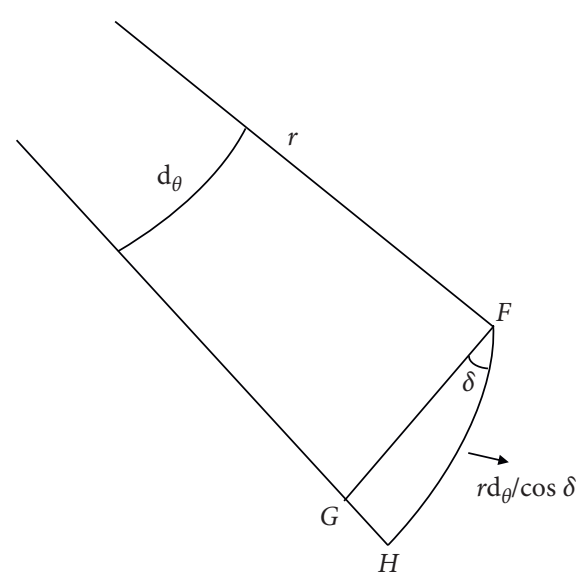

Figure 4: Slope element considering tension cut-off.

$$
W_{r}+W_{s}+W_{q t}=D
$$

where $W_{\mathrm{r}}$ is the energy dissipation rate under the weight of soil, $W_{\mathrm{s}}$ is the energy dissipation rate under the quasistatic seismic, $W_{q t}$ is the power under the surcharge, and $D$ is the internal energy dissipation rate of the sliding block BDEC. The external powers $W_{r}$ and $W_{r}$ can be expressed as the powers of block $\mathrm{ABC}$ minus block $\mathrm{ADE}$ specifically as follows:

$$
\begin{aligned}
& W_{r}=W_{r 1}-W_{r 2}-W_{r 3}-\left(W_{r 4}-W_{r 5}-W_{r 6}\right)=\gamma w r_{0}^{3} f_{w} \\
& W_{s}=W_{s 1}-W_{s 2}-W_{s 3}-\left(W_{s 4}-W_{s 5}-W_{s 6}\right)=k \gamma w r_{0}^{3} f_{s} \\
& W_{q t}=q_{t} * f_{q} .
\end{aligned}
$$

Subscripts 1 to 6 in the formula, respectively, represent the energy dissipation of OCA, AOB, BOC, OEA, AOD, and DOE in Figure 2, where $f_{w}$ and $f_{s}$ are functional equations including variables $\beta, \theta_{0}, \theta_{t c}, \theta_{m}$, and $\theta_{h}$. When analyzing the 
power of surcharge, the surcharge factor $q_{t}$ is introduced, and $f_{q}$ is the surcharge function. According to the principal strain rate, the internal energy dissipation caused by the tension zone cut-off is $c w r_{0}^{3} f_{\mathrm{dc}}$; then the work done by the whole sliding surface can be expressed as

$$
D=D_{D E}+D_{C E}=c w r_{0}^{2} f_{d}+c w r_{0}^{2} f_{d c}
$$

where $f_{\mathrm{d}}$ is a function of variables $\theta_{t c}, \theta_{h}$, and $\varphi$, while $f_{\mathrm{dc}}$ is a function of variables $\theta_{t c}, \theta_{m}$, and $\varphi$. Refer to the Appendix for detailed expressions of $f_{\mathrm{w}}, f_{\mathrm{s}}, f_{\mathrm{d}}, f_{\mathrm{dc}}$, and $f_{q}$.

The expression of critical acceleration $K_{c}$ can be obtained by arranging the above formula:

$$
K_{c}=\frac{(1 / 2 \tan \varphi) \times\left(H / r_{0}\right) \times(c / \gamma H) \times\left(D_{D E}+D_{C E}\right)-\left(f_{1}-f_{2}-f_{3}-t_{1}+t_{2}+t_{3}+q_{t} * f_{q}\right)}{\left(f_{1 s}-f_{2 s}-f_{3 s}-f_{4 s}+f_{5 s}+f_{6 s}\right)},
$$

where $K_{c}$ is a function of parameters such as $\theta_{0}, \theta_{t c}, \theta_{m}, \theta_{h}$, $c / \gamma H$, slop inclination $\beta$, and internal friction angle $\varphi$; the critical acceleration $K_{c}$ is the minimum value under a series of variable combinations.

3.2. Calculation Optimization Algorithm. In order to search the critical value of $K_{c}$ under the parameters of $\theta_{0}, \theta_{t c}, \theta_{m}, \theta_{h}$, $c / \gamma H, \beta, \varphi$, and so forth, the derivation analysis of $K_{c}$ should be carried out. The specific limitation and calculations are as follows:

$$
\begin{array}{r}
0<\theta_{0}<\theta_{m}<\theta_{t c}<\theta_{h}<\pi, \\
\frac{\partial k_{c}^{\prime}}{\theta_{0}}=\frac{\partial k_{c}^{\prime}}{\theta_{m}}=\frac{\partial k_{c}^{\prime}}{\theta_{t c}}=\frac{\partial k_{c}^{\prime}}{\theta_{h}}=0 .
\end{array}
$$

Based on limitation, the critical acceleration is solved by new combination method. Traditional calculation methods have some defects, such as low speed of the ergodic calculation, low accuracy of the random search method, and optimal solution being inclined to fall into local optima. In this paper, the random search method and the sequential quadratic optimization method are used to analyze and solve the problem. Although the accuracy of the random search method is lower, it can give a range of the initial value. After getting a more reasonable initial value, the sequential quadratic optimization can be used to search the critical value. See Appendix B for the detailed algorithm. Some verification results are shown in Table 1 and Table 2, where the design parameters are given in Table 1. Meanwhile the classical and FEM solutions are presented in Table 2, and the classical solution refers to [20]. The calculation results in this paper are in reasonable agreement with the classical solutions and are close to the results verified by the FEM software Optum-G2, while the critical acceleration is more unfavorable. Therefore, the slip surface calculated in this paper lies between the upper and lower limits of the FEM (shown as Figure 5) and is in a reasonable range.

\section{Calculation of Critical Acceleration}

Considering various parameters, surcharge factor $q_{t}=0-0.3$, slop inclination $\beta=30^{\circ}-90^{\circ}$, internal friction angle $\varphi=10^{\circ}-30^{\circ}, c / \gamma H=0.1-0.25$, and reduction coefficient $\xi=0-1$, the stability of surcharged slope is analyzed. The nonlinear coefficient $\xi=1$ represents the results of linear $\mathrm{M}-\mathrm{C}$ yield analysis. Therefore, the verification results of the parameters in Table 1 when $\xi=1$ with the classical results and the FEM software Optum-G2 calculation are shown in Table 2. Results show that the present solutions match the classical results and FEM ones very well. To distinguish between the two failure modes shown in Figure 3, from Figures 6-9, the upper point line without symbol represents the below-toe failure ("below-toe failure" in Figure 6(a)), and the rest of the lines with different symbols represent the toe failure ("toe failure" in Figure 6(a)). Toe failure is the characteristic of a tribological soil, while the internal friction angle is small and the slope angle is moderate; the below-toe failure is more likely to occur. However, when considering the influence of seismic loads, the slope with larger internal friction angle is also prone to below-toe failure. As shown in Figures 6-9, the critical acceleration reduces rapidly when considering the influence of tension cut-off, and the failure is more intense for the slope with small internal friction angle and large slop inclination. For example, considering the failure condition, $\beta=50^{\circ}, \varphi=30^{\circ}, c / \gamma H=0.15$, and $\xi=0$, the critical acceleration for surcharged slope from $q_{t}=0$ to $q_{t}=0.3$ is $K_{c}=0.430 \mathrm{~g}, 0.403 \mathrm{~g}, 0.370 \mathrm{~g}$, and $0.333 \mathrm{~g}$ respectively, with the reduction of $23 \%$. When considering smaller internal friction angle and slope angle, the impact will be even greater. As a result, surcharge will accelerate the reduction of critical acceleration.

\section{Deduction of Permanent Displacement}

Pseudostatic method is usually used to equivalent the seismic load on the slope during the design. In order to analyze the influence of dynamic loading on the slope and further understand the influence of various surcharge factors and tension cut-off factors, permanent displacement calculation results of the slope based on various seismic records should be obtained.

In the framework of the upper limit theorem of limit analysis, Chang et al. [21] proposed a method to solve the permanent displacement of slope with rotating failure surfaces. The rotation logic diagram is shown in Figure 10 and the calculation process is described as follows: when the seismic coefficient $K$ exceeds the critical acceleration $K_{c}$, the block begins to slide. By balance power equation, the angular acceleration of rotation can be obtained as follows: 
TABLE 1: Design parameter.

\begin{tabular}{lcccc}
\hline Slope inclination $\left(^{\circ}\right)$ & Cohesion $(\mathrm{kPa})$ & Internal friction angle $\left(^{\circ}\right)$ & Unit density $^{\circ}\left(\mathrm{kN} \cdot \mathrm{m}^{-3}\right)$ & Slope height $(\mathrm{m})$ \\
\hline $30^{\circ}-90^{\circ}$ & 30 & 30 & 15 & 10 \\
\hline
\end{tabular}

TABle 2: Comparison of different algorithms' results.

\begin{tabular}{lccc}
\hline Slope inclination $\left(^{\circ}\right)$ & The present solutions & The classical solutions & The FEM solutions \\
\hline 30 & $\mathbf{0 . 7 0 6}$ & 0.706 & 0.704 \\
40 & $\mathbf{0 . 6 8 0}$ & 0.683 & 0.690 \\
50 & $\mathbf{0 . 6 1 2}$ & 0.615 & 0.644 \\
60 & $\mathbf{0 . 5 3 6}$ & 0.536 & 0.567 \\
70 & $\mathbf{0 . 4 4 2}$ & 0.443 & 0.475 \\
80 & $\mathbf{0 . 3 2 9}$ & 0.322 & 0.361 \\
90 & $\mathbf{0 . 1 9 2}$ & 0.194 & 0.231 \\
\hline
\end{tabular}

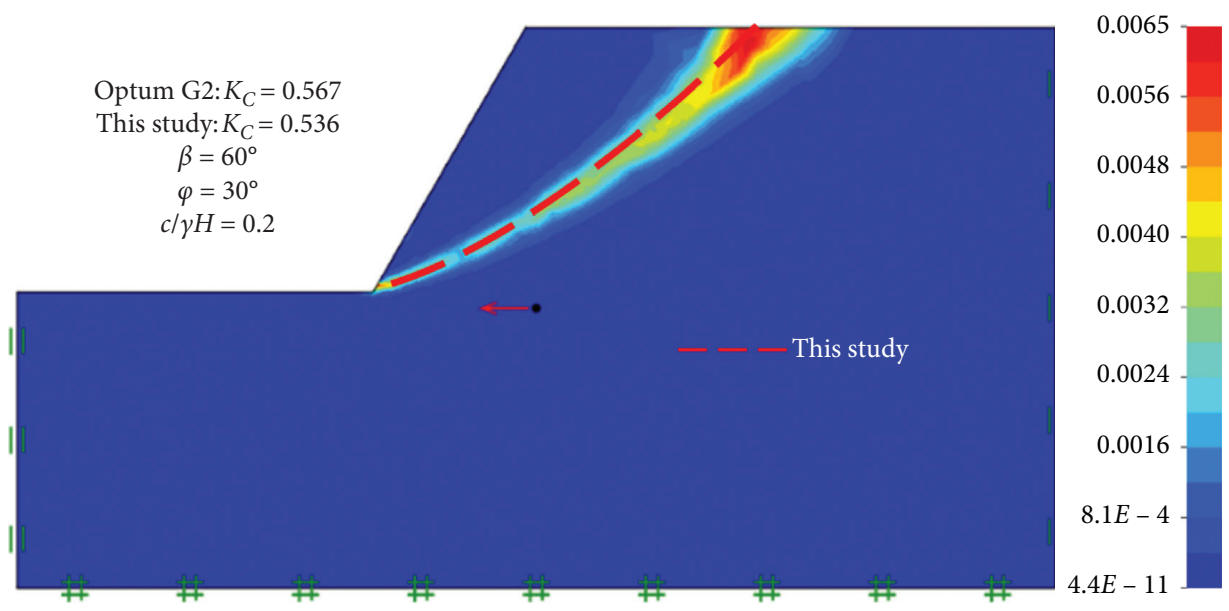

FIGURE 5: Comparison between results from this paper and FEM ones.
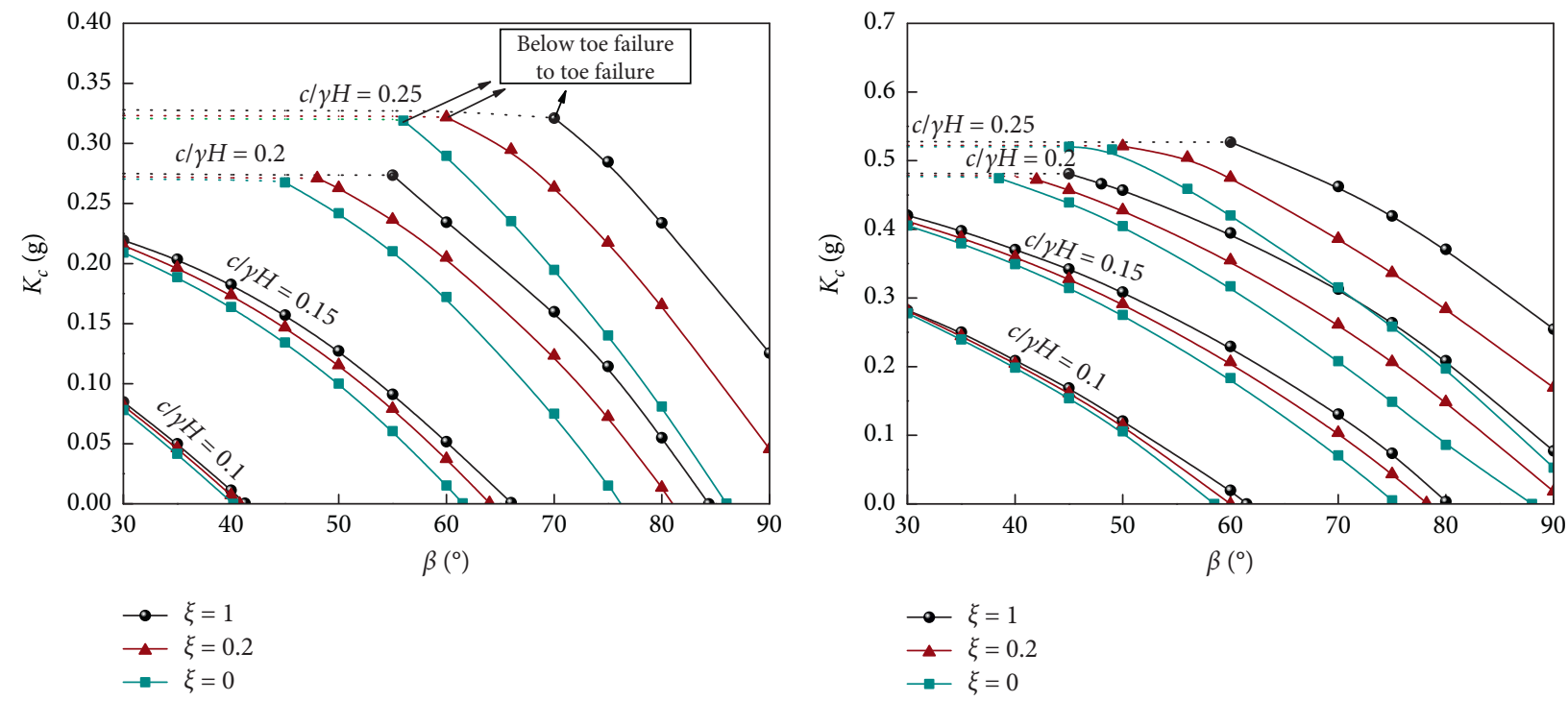

(a)

(b)

FIgURE 6: Continued. 


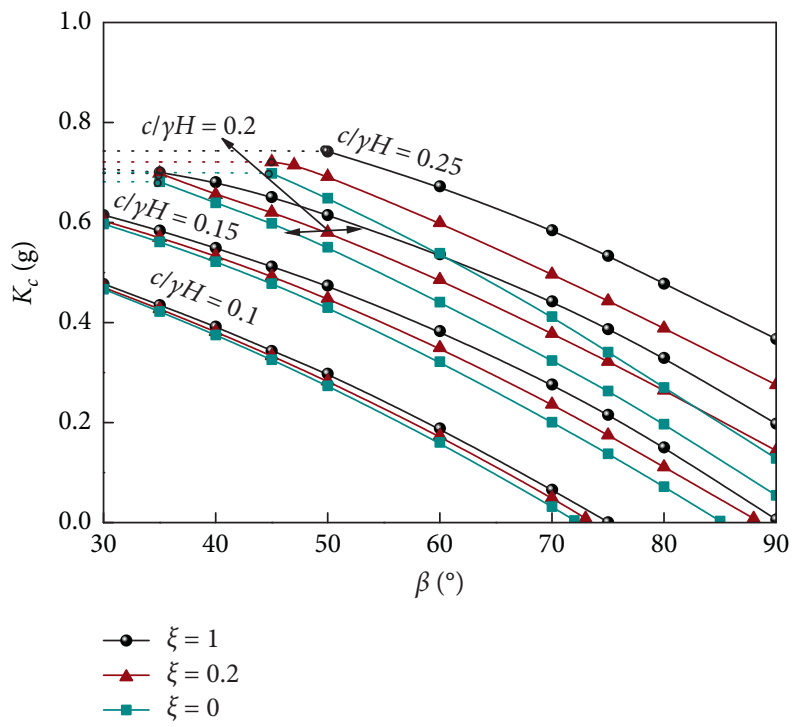

(c)

Figure 6: Critical accelerations of slope under surcharge factor of $q_{t}=0$ with various nonlinear coefficients. (a) $\varphi=10^{\circ}$. (b) $\varphi=20^{\circ}$. (c) $\varphi=30^{\circ}$.
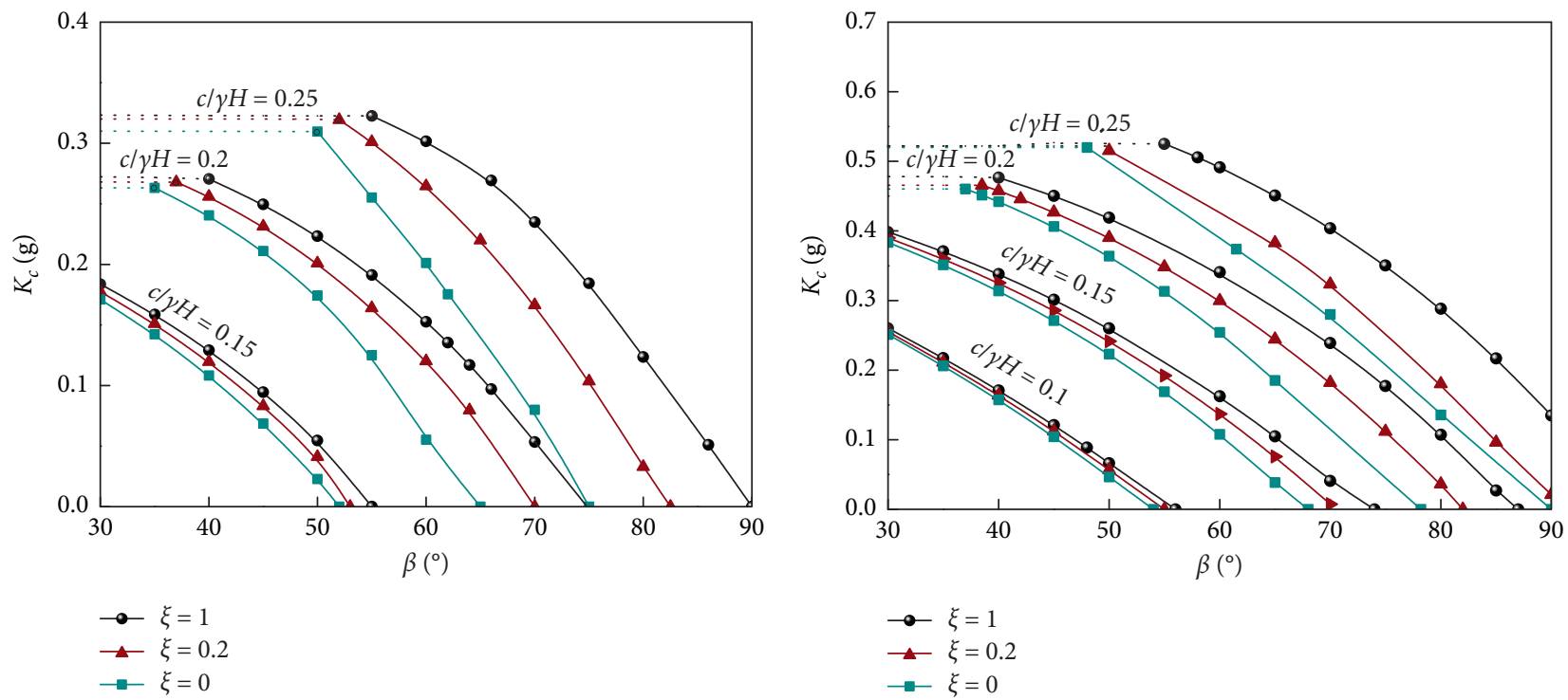

(a)

(b)

Figure 7: Continued. 


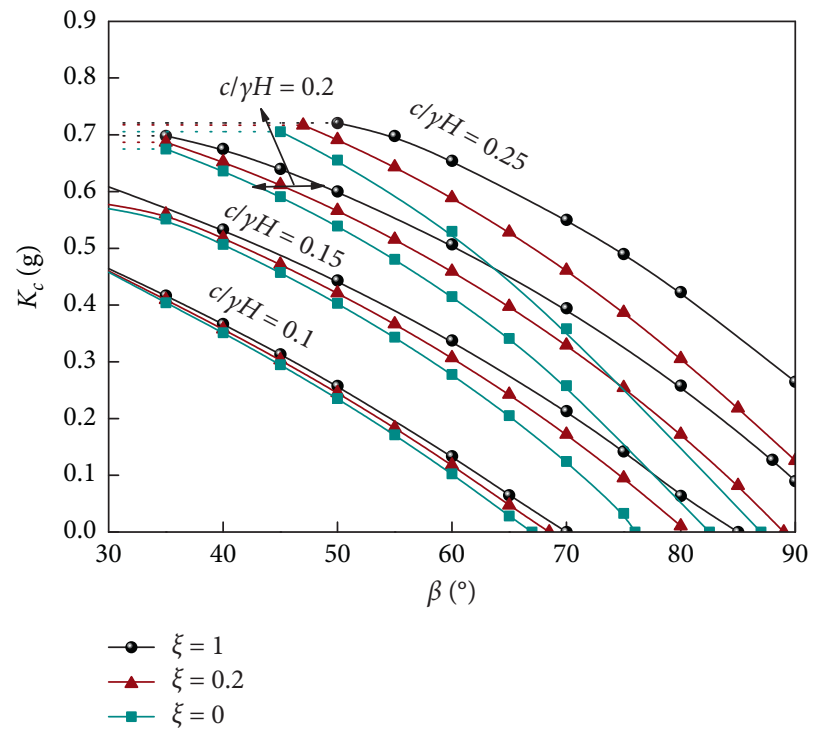

(c)

FiguRE 7: Critical accelerations of slope under surcharge factor of $q_{t}=0.1$ with various nonlinear coefficients. (a) $\varphi=10^{\circ}$. (b) $\varphi=20^{\circ}$. (c) $\varphi=30^{\circ}$.

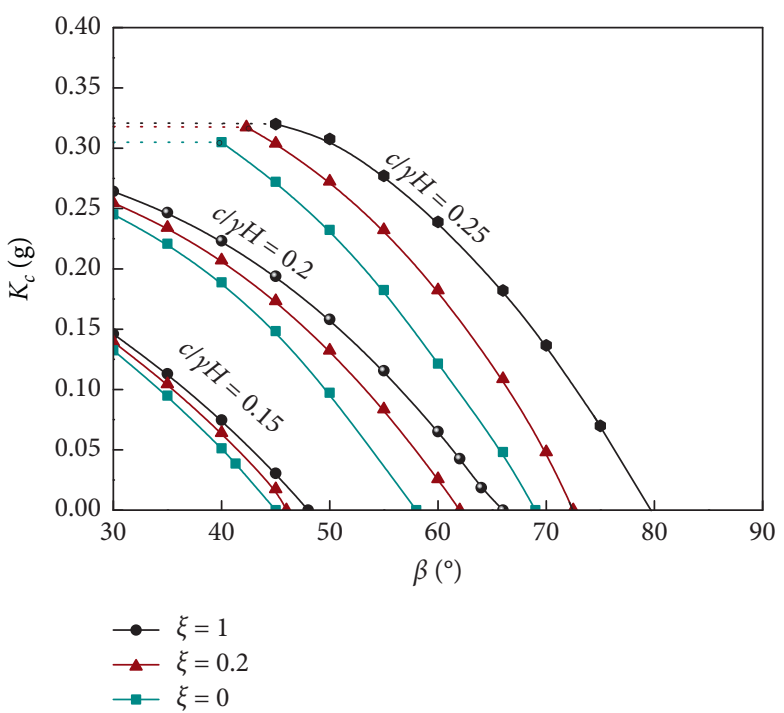

(a)

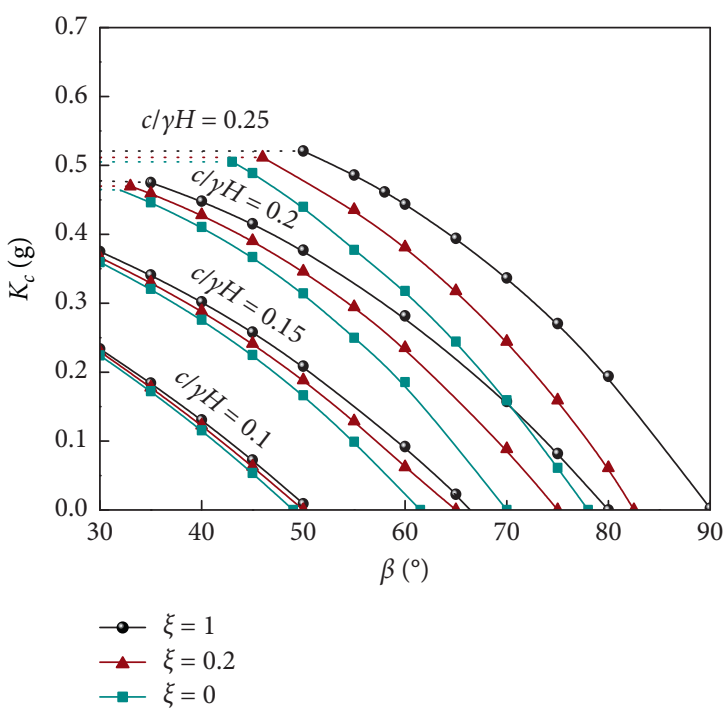

(b)

Figure 8: Continued. 


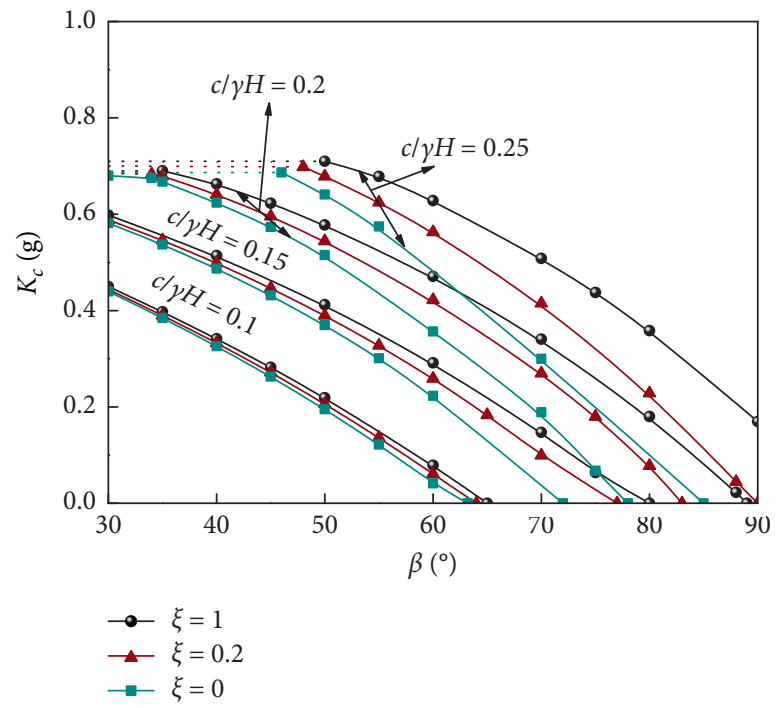

(c)

FiguRE 8: Critical accelerations of slope under surcharge factor of $q_{t}=0.2$ with various nonlinear coefficients. (a) $\varphi=10^{\circ}$. (b) $\varphi=20^{\circ}$. (c) $\varphi=30^{\circ}$.

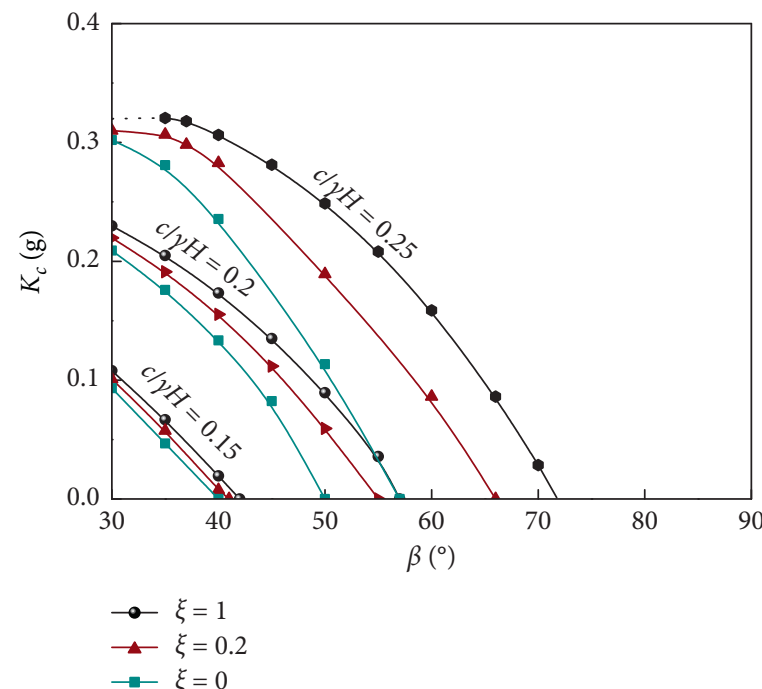

(a)

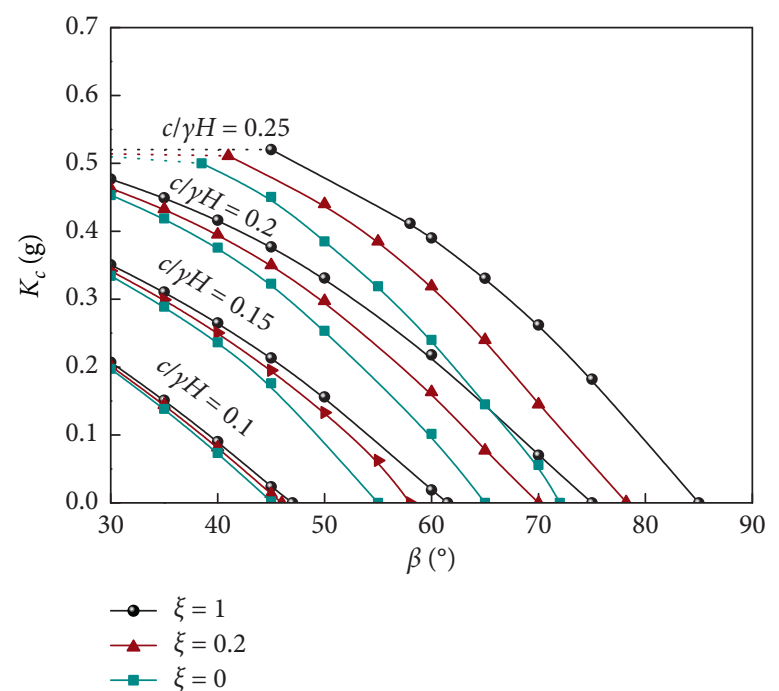

(b)

Figure 9: Continued. 


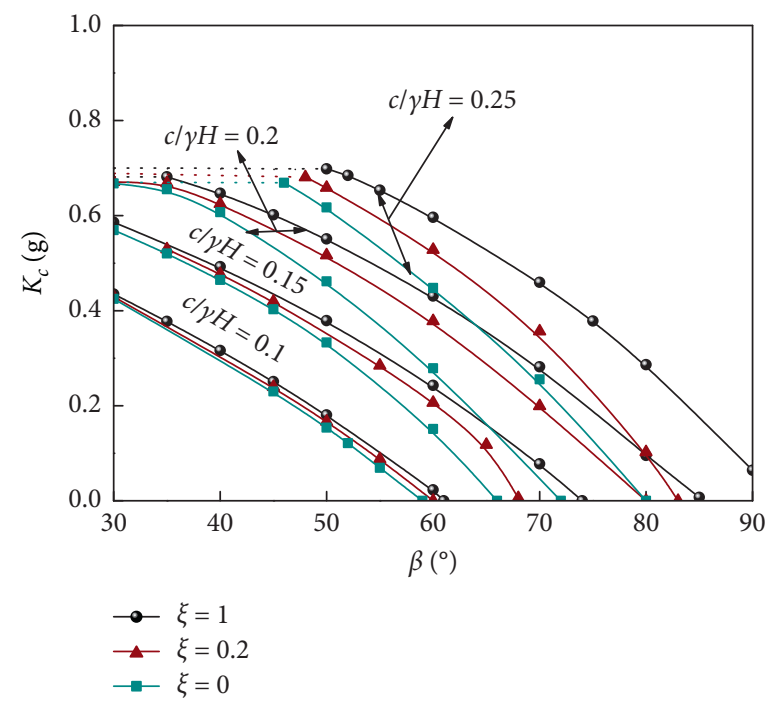

(c)

FIGURE 9: Critical accelerations of slope under surcharge factor of $q_{t}=0.3$ with various nonlinear coefficients. (a) $\varphi=10^{\circ}$. (b) $\varphi=20^{\circ}$. (c) $\varphi=30^{\circ}$.

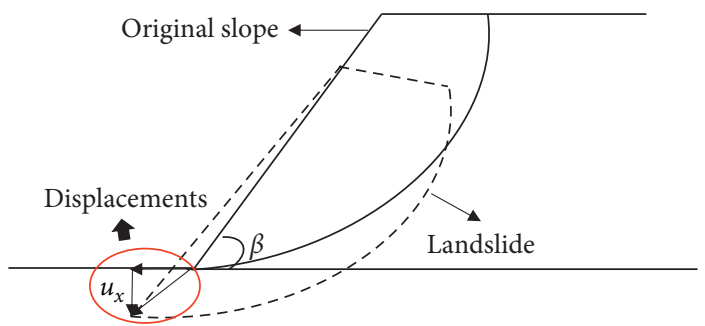

Figure 10: Slope rotational mechanism under analysis of tension cut-off.

$$
\ddot{\theta}=\frac{\gamma r_{0}^{3}}{G l^{2}} g\left(k-k_{c}\right)\left(f_{1 s}-f_{2 s}-f_{3 s}-f_{4 s}+f_{5 s}+f_{6 s}\right),
$$

where $G$ is the gravity of the slider (the BDEC part in Figure 2(a)) and $l$ is the distance from the rotation center $O$ to the center of gravity. The horizontal permanent displacement of the slope toe is calculated by the double integral as follows:

$$
u_{x}=r_{h} \sin \theta_{h} \int_{t} \int_{t} \ddot{\theta} \mathrm{d} t \mathrm{~d} t
$$

\section{Case Analysis of Earthquake Damage}

During the 1994 Northridge earthquake in USA, approximately 11,000 houses collapsed in Los Angeles region during the initial 30 seconds of the ground motion. Highways and high-rise buildings within 30 kilometers of the epicenter were destroyed or collapsed. Gas and water pipes burst, telecommunication was interrupted, and fires broke out.
58 people died directly or indirectly, and 600 people were injured; and more than 30 billion US dollars loss of property was caused [15]. We consider two seismic records of Northridge earthquake as research objects and the seismic records, respectively, from Moorpark Station and Rinaldi Receiving Station; refer to Table 3 for detailed parameter information of the records, and Figure 11 shows station distribution area information and Figure 12 shows the acceleration-time history in the horizontal direction. In order to validate the results of this study in permanent displacement, the comparison part selected in this research is $c / \gamma H=0.1, \beta=55^{\circ}$, and $\varphi=20^{\circ}$ under the influence of record from Moorpark Station, the same as Utili and Abd [23] and He et al. [12]. Detailed comparison results are shown in Table 4. While comparing the influence of overload factor, this research considered the parameters as $c / \gamma H=0.15$, $\beta=55^{\circ}$, and $\varphi=30^{\circ}$ under the record from Rinaldi Receiving Station.

The verification result shows that the permanent displacement calculated in this paper is very close to the previous solution and belongs to a reasonable interval in 
TABLE 3: Main characteristics of earthquake records.

\begin{tabular}{lcc}
\hline Earthquake & Northridge earthquake & Northridge earthquake \\
\hline Time & $1994-01-17$ & $1994-01-17$ \\
Recording station & Moorpark & Rinaldi Receiving \\
Magnitude & 6.7 & 6.7 \\
PGA/g & 0.292 & 0.841 \\
Interval time/d $t$ & 0.02 & 0.01 \\
\hline
\end{tabular}

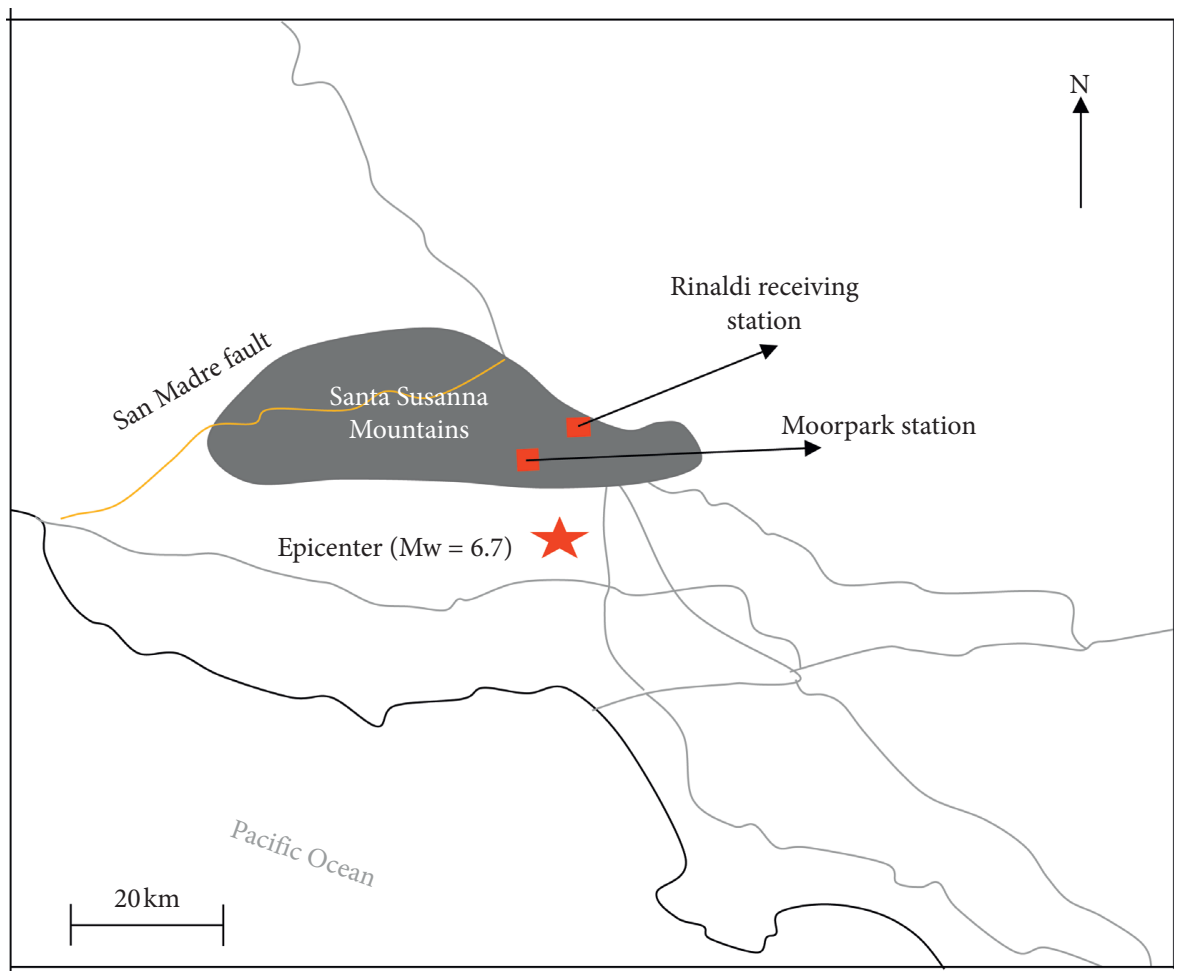

FIGURE 11: Station information of Northridge earthquake (modified by Jibson et al., [22]).

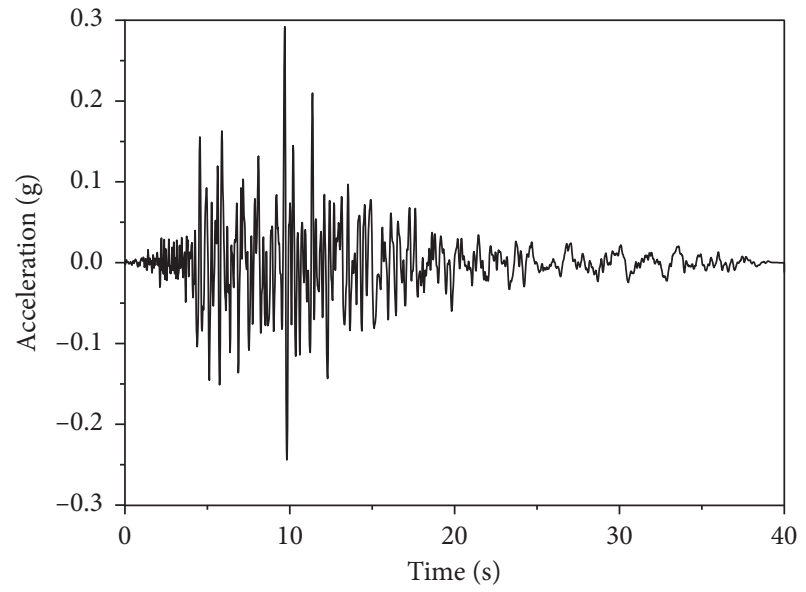

(a)

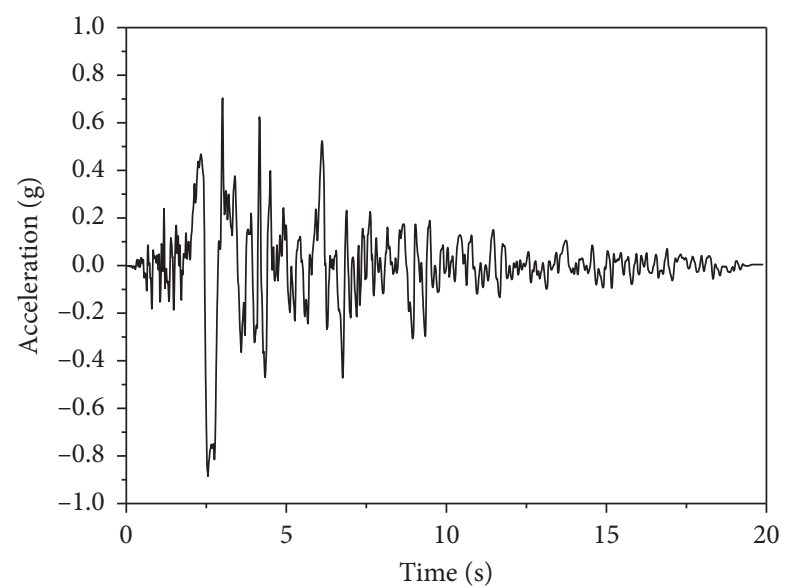

(b)

Figure 12: Acceleration-time history of ground motions. (a) Northridge earthquake Moorpark station PGA=0.292 g. (b) Northridge earthquake Pinadl receiving station PGA $=0.841 \mathrm{~g}$. 
TABle 4: Verification of permanent displacement.

\begin{tabular}{lcc}
\hline Nonlinear coefficient & Classic results [12] & This research \\
\hline$\xi=0$ & 14.756 & 14.750 \\
$\xi=0.2$ & 9.581 & 9.577 \\
$\xi=0.5$ & 7.415 & 7.407 \\
$\xi=1$ & $7.236 / 7.134[23]$ & 7.213 \\
\hline
\end{tabular}

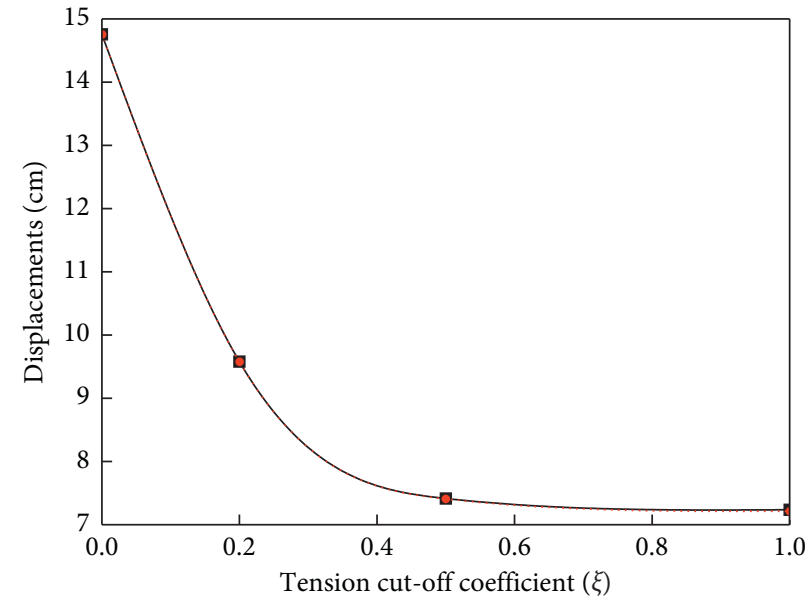

$\rightarrow-\operatorname{He}(2019)$

-.. This research

FIGURE 13: Verification of permanent displacement.

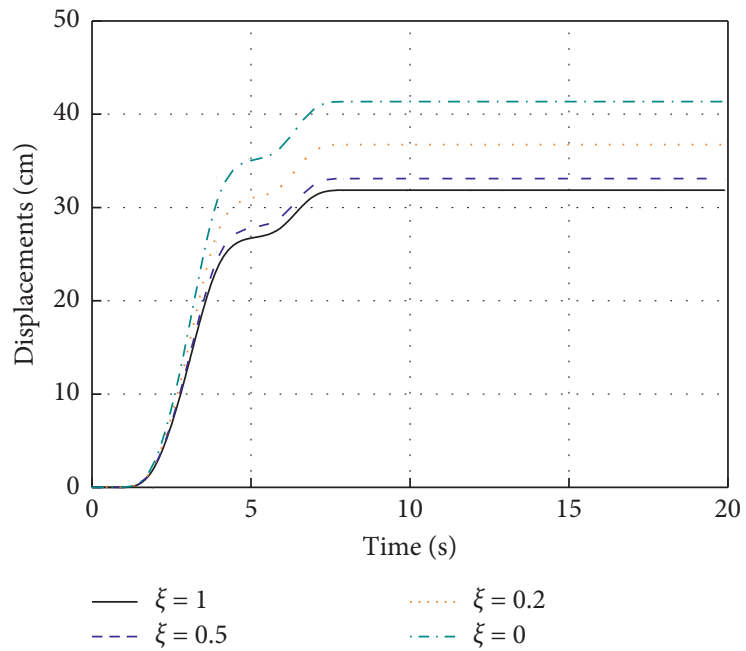

(a)

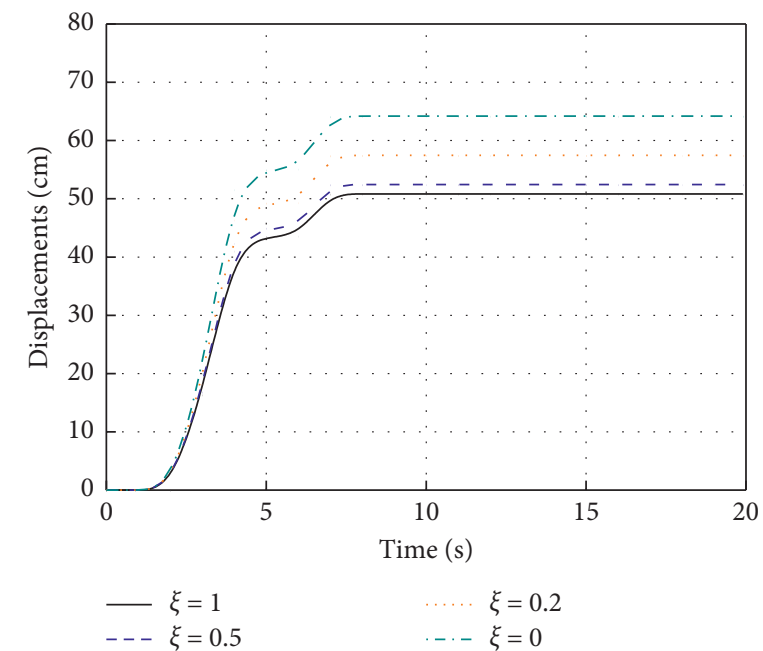

(b)

FIgURE 14: Continued. 


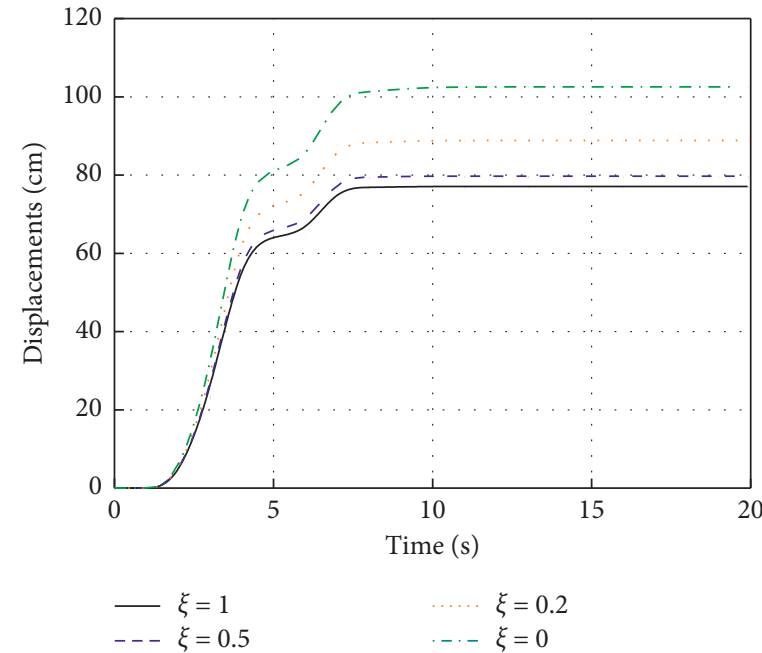

(c)

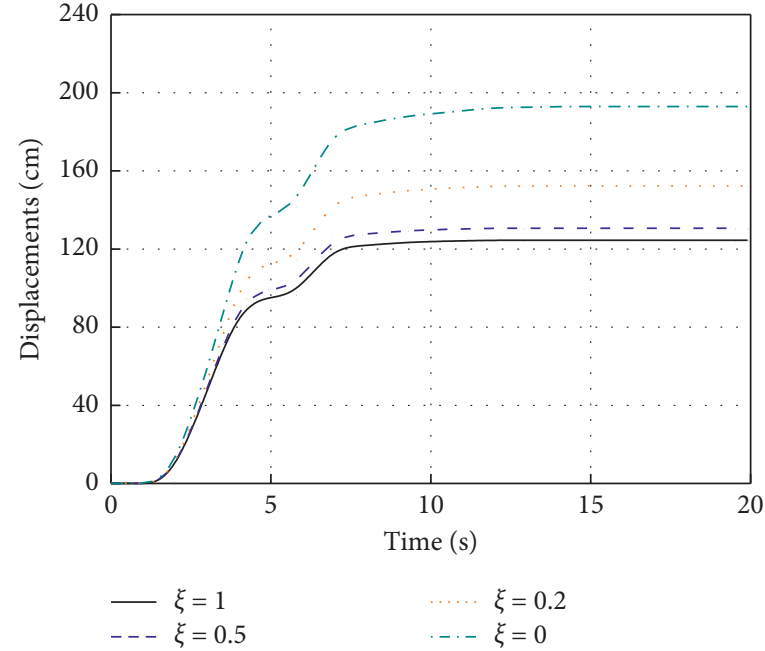

(d)

Figure 14: Permanent displacement of surcharge slope considering tension cut-off (Northridge earthquake).

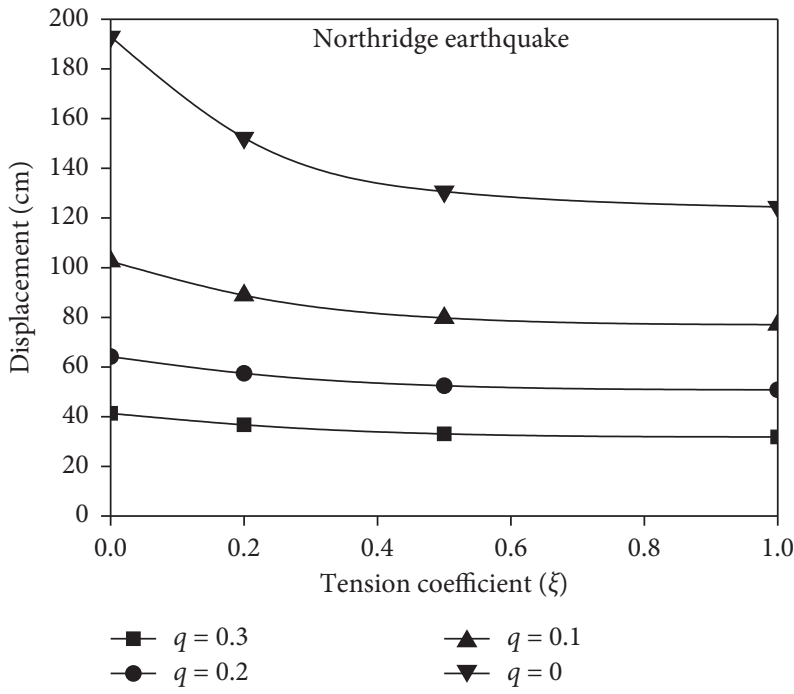

FIGURE 15: Distribution of permanent displacement of surcharge slope considering tension cut-off.

Figure 13. The information from Table 4 shows that the displacement of slope with full tensile cut-off is $14.75 \mathrm{~cm}$, more than 2 times the slope with no tension cut-off $(7.21 \mathrm{~cm})$. Figures 14 and 15 show the permanent displacement of the surcharged slope considering tension cutoff in the case of Northridge earthquake. The result shows that the permanent displacement will increase significantly when considering tension cut-off. For example, in the case of $q_{t}=0.3$, the displacements under the $\mathrm{M}-\mathrm{C}$ criterion and $\xi=0$ are $126.4 \mathrm{~cm}$ and $192.8 \mathrm{~cm}$, respectively, and increase by $52.53 \%$ after considering the strength cut-off. As shown in Figure 15, the influence of tensile strength on the permanent displacement is not obvious, when the tension cut-off coefficient $\xi$ is from 0.4 to 1 , while when $\xi$ approaches 0 , the permanent displacement increases rapidly, which indicates the great influence of tension cut-off coefficient. The reduction of permanent displacement considering surcharge effect is significantly greater than that of nonsurcharge slope. 


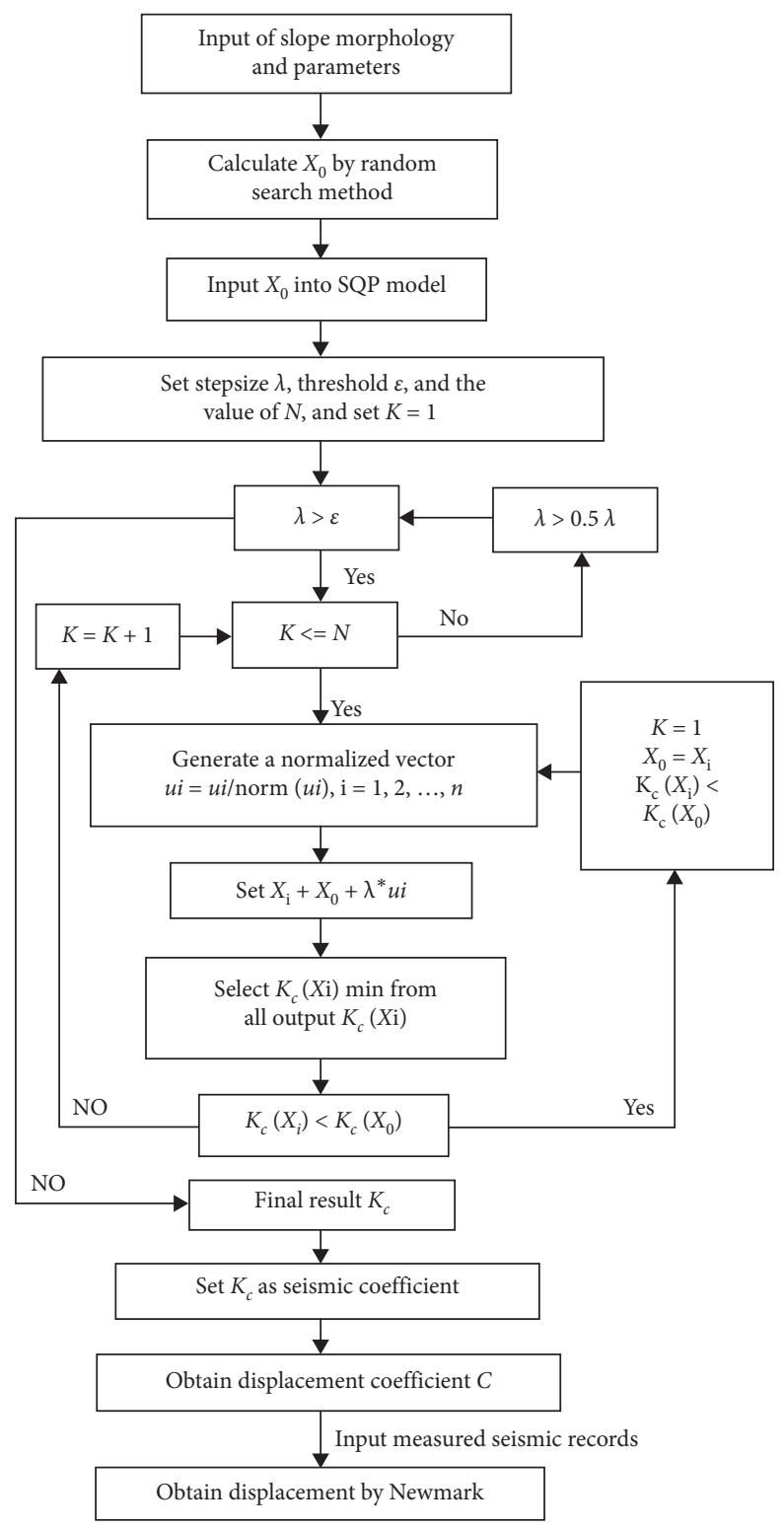

Figure 16: Flow chart of optimization algorithm.

\section{Conclusion}

Based on the kinematic theory of limit analysis, this paper described the detailed theoretical analysis of slope with tension cut-off and studied the effect of surcharge on the stability of slope under seismic conditions. Analyses using the pseudostatic method and Newmark method are carried out to evaluate the behavior of slope under dynamic loading, and the critical accelerations and permanent displacements of the surcharge slope under various tensile strength cut-off are calculated. In order to obtain the minimum upper limit solution, the random search method and comprehensive optimization analysis are used and compared with the results of the classical solution and the FEM software Optum-G2. The research outcomes show the following:
(1) The random search method and SQP significantly enhance the efficiency of calculation. The calculation results are between the upper and lower limits of the FEM, which are in a reasonable range.

(2) The reduction coefficient $\xi$ of the tensile stress area influences the critical acceleration $K_{c}$ greatly. The influence increases with increase in surcharge, and the slope with larger slope angle and smaller internal friction angle is more vulnerable to damage.

(3) Considering tensile strength cut-off and surcharge, the permanent displacement of the slope will be more than twice that under the traditional M-C criterion, and, with tensile strength cut-off increasing, the displacement accumulation will be more rapid and exacerbated by surcharge effect. 


\section{Appendix}

\section{A. Calculation Formula}

$$
\begin{aligned}
& f_{1}=\frac{e^{3\left(\theta_{h}-\theta_{0}\right) \tan \varphi}\left(3 \tan \varphi \cos \theta_{h}+\sin \theta_{h}\right)-3 \tan \varphi \cos \theta_{0}-\sin \theta_{0}}{3\left(1+9 \tan ^{2} \varphi\right)}, \\
& f_{2}=\frac{1}{6} \sin \theta_{0} \frac{L_{1}}{r_{0}}\left(2 \cos \theta_{0}-\frac{L_{1}}{r_{0}}\right) \\
& f_{3}=\frac{1}{6} e^{\left(\theta_{h}-\theta_{0}\right) \tan \varphi}\left[\sin \left(\theta_{h}-\theta_{0}\right)-\frac{L_{1}}{r_{0}} \sin \theta_{h}\right] \cdot\left(\cos \theta_{0}-\frac{L_{1}}{r_{0}}+e^{\left(\theta_{h}-\theta_{0}\right) \tan \varphi} \cos \theta_{h}\right), \\
& f_{1 s}=\frac{1}{2}\left(\frac{H}{r_{0}}\right)^{2} \cdot\left[\cos \theta_{0}-\frac{L_{1}}{r_{0}}-\frac{1}{3} \frac{H}{r_{0}}(2 \cdot \cot \beta)\right] \text {, } \\
& f_{2 s}=\frac{e^{3 \tan \varphi\left(\theta_{h}-\theta_{0}\right)}\left(3 \tan \varphi \sin \theta_{h}-\cos \theta_{h}\right)-3 \tan \varphi \sin \theta_{0}+\cos \theta_{0}}{3\left(1+9 \tan ^{2} \varphi\right)}, \\
& f_{3 s}=\frac{1}{3} \frac{L_{1}}{r_{0}} \sin ^{2} \theta_{0} \\
& f_{4}=\frac{e^{3\left(\theta_{t c}-\theta_{0}\right) \tan \varphi}\left(3 \tan \varphi \cos \theta_{t c}+\sin \theta_{t c}\right)-\sin \theta_{0}-3 \cos \theta_{0} \tan \varphi}{3\left(1+9 \tan ^{2} \varphi\right)}, \\
& f_{5}=\frac{1}{6}\left(\frac{1}{\tan ^{2} \theta_{0}}-\frac{1}{\tan ^{2} \theta_{m}}\right) \sin ^{3} \theta_{0} \\
& f_{6}=\frac{1}{3} \frac{\sin ^{3} \theta_{0}}{\sin ^{3} \theta_{m}} \int_{\theta_{m}}^{\theta_{t c}} e^{3\left(\theta_{t c}-\theta_{m} / \delta_{m}-\varphi\right) \ln \left(\cos \delta(\theta) / \cos \delta_{m}\right)} \sin \theta \mathrm{d} \theta, \\
& f_{4 s}=\frac{e^{3\left(\theta_{t c}-\theta_{0}\right) \tan \varphi}\left(3 \tan \varphi \sin \theta_{t c}-\cos \theta_{t c}\right)+\cos \theta_{0}-3 \sin \theta_{0} \tan \varphi}{3\left(1+9 \tan ^{2} \varphi\right)}, \\
& f_{5 s}=\frac{1}{3}\left(\frac{1}{\tan \theta_{0}}-\frac{1}{\tan \theta_{m}}\right) \sin ^{3} \theta_{0}, \\
& f_{6 s}=\frac{1}{3} \frac{\sin ^{3} \theta_{0}}{\sin ^{3} \theta_{m}} \int_{\theta_{m}}^{\theta_{t c}} e^{3\left(\theta_{t c}-\theta_{m} / \delta_{m}-\varphi\right) \ln \left(\cos \delta(\theta) / \cos \delta_{m}\right)} \sin \theta \mathrm{d} \theta \\
& f_{d c}=c w r_{0}^{2} \frac{\sin ^{2} \theta_{0}}{\sin ^{2} \theta_{m}} \frac{\cos \varphi}{1-\sin \varphi} \int_{\theta_{m}}^{\theta_{t c}} e^{2 \int_{\theta_{m}}^{\theta} \tan \delta(\theta)} \times \frac{1}{\cos \delta}\left(1-\sin \delta+2 \xi \frac{\sin \delta-\sin \varphi}{1+\sin \varphi}\right) \mathrm{d} \theta, \\
& f_{d}=\frac{e^{2\left(\theta_{h}-\theta_{0}\right) \tan \varphi}-e^{2\left(\theta_{t c}-\theta_{0}\right) \tan \varphi}}{2 \tan \varphi}
\end{aligned}
$$


where $\theta_{0}, \theta_{t c}$, and $\theta_{m}$ must satisfy the implicit equation:

$$
\begin{aligned}
& \cos \delta_{m}=\exp \left\{-\frac{\delta_{m}-\varphi}{\theta_{t c}-\theta_{m}} \ln \left[\frac{\sin \theta_{m}}{\sin \theta_{0}} e^{\left(\theta_{t c}-\theta_{0}\right) \tan \varphi}\right]\right\} \cos \varphi, \\
& f_{q}=\frac{L_{2}}{r_{0}} \frac{H}{r_{0}}\left[\cos \theta_{0}-\frac{1}{2} \frac{L_{2}}{r_{0}}\right] \\
& \frac{H}{r_{0}}=e^{\tan \varphi\left(\theta_{h}-\theta_{0}\right)} \sin \theta_{h}-\sin \theta_{0}, \\
& \frac{L_{1}}{r_{0}}=\frac{\sin \left(\theta_{h}-\theta_{0}\right)}{\sin \theta_{h}}-\left\{e^{\left(\theta_{h}-\theta_{0}\right) \tan \varphi} \sin \theta_{h}-\theta_{0}\right\} \frac{\sin \left(\theta_{h}+\beta\right)}{\sin \beta \sin \theta_{h}}, \\
& \frac{L_{2}}{r_{0}}=\frac{\sin \left(\theta_{m}-\theta_{0}\right)}{\sin \theta_{m}}-\frac{\cos \theta_{m}}{\sin \theta_{m}}\left\{e^{\left(\theta_{m}-\theta_{0}\right) \tan \varphi} \sin \theta_{m}-\sin \theta_{0}\right\} .
\end{aligned}
$$

\section{B. Flow Chart of Optimization Algorithm}

Flow Chart of Optimization Algorithm is shown in Figure 16.

\section{Data Availability}

The data used to support the findings of this study are available from the corresponding author upon request.

\section{Conflicts of Interest}

The authors declare that they have no conflicts of interest.

\section{Acknowledgments}

This study was financially supported by the National Natural Science Foundation of China (no. 51268003). The financial support is greatly appreciated.

\section{References}

[1] K. Terzhagi, Mechanism of Landslides. Application of Geology to Engineering Practice (Berkey Volume), Geological Society of America, New York, NY, USA, 1950.

[2] N. M. Newmark, "Effects of earthquakes on dams and embankments," Géotechnique, vol. 15, no. 2, pp. 139-160, 1965.

[3] J. D. Bray and E. M. Rathje, "Earthquake-Induced displacements of solid-waste landfills," Journal of Geotechnical and Geoenvironmental Engineering, vol. 124, no. 3, pp. 242-253, 1998.

[4] E. M. Rathje and J. D. Bray, "Nonlinear coupled seismic sliding analysis of earth structures," Journal of Geotechnical and Geoenvironmental Engineering, vol. 126, no. 11, pp. 1002-1014, 2000.

[5] D. W. Taylor, "Fundamentals of soil mechanics," Soil Science, vol. 66, no. 2, p. 161, 1948.

[6] D. C. Drucker and W. Prager, "Soil mechanics and plastic analysis or limit design," Quarterly of Applied Mathematics, vol. 10, no. 2, pp. 157-165, 1952.
[7] R. L. Michalowski, "Stability assessment of slopes with cracks using limit analysis," Canadian Geotechnical Journal, vol. 50, no. 10, pp. 1011-1021, 2013.

[8] D. Park and R. L. Michalowski, "Three-dimensional stability analysis of slopes in hard soil/soft rock with tensile strength cut-off," Engineering Geology, vol. 229, pp. 73-84, 2017.

[9] Z.-W. Li, X.-L. Yang, and T.-Z. Li, "Static and seismic stability assessment of 3D slopes with cracks," Engineering Geology, vol. 265, Article ID 105450, 2020.

[10] E. Jamalinia, P. J. Vardon, and S. C. Steele-Dunne, "The impact of evaporation induced cracks and precipitation on temporal slope stability," Computers and Geotechnics, vol. 122, Article ID 103506, 2020.

[11] D. Park, Z. Wang, and R. L. Michalowski, Consequences of Seismic Excitation on Slopes in Soils with a Tensile Strength Cutoff, Geotechnical Frontiers, ASCE Library, Reston VA, USA, 2017.

[12] Y. He, Y. Liu, H. Hazarika, and R. Yuan, "Stability analysis of seismic slopes with tensile strength cut-off," Computers and Geotechnics, vol. 112, pp. 245-256, 2019.

[13] G. Tang, L. Zhao, L. Liang et al., "Stability design charts for homogeneous slopes under typical conditions based on the double shear strength reduction technique," Arabian Journal of Geosciences, vol. 10, no. 13, p. 280, 2017.

[14] B. Paul, "A modification of the coulomb-mohr theory of fracture," Journal of Applied Mechanics, vol. 28, no. 2, 1961.

[15] K. J. Tierney, "Business impacts of the Northridge earthquake," Journal of Contingencies and Crisis Management, vol. 5, no. 2, pp. 87-97, 1997.

[16] C. Qin and S. C. Chian, "Seismic bearing capacity of nonuniform soil slopes using discretization-based kinematic analysis considering rayleigh waves," Soil Dynamics and Earthquake Engineering, vol. 109, pp. 23-32, 2018.

[17] C.-B. Qin, S. C. Chian, and G. Gazetas, "Kinematic analysis of seismic slope stability with discretisation technique and pseudo-dynamic approach: a new perspective," Géotechnique, vol. 69, no. 11, pp. 1031-1033, 2019.

[18] J. Zheng, Q. Lü, J. Deng, X. Yang, X. Fan, and Z. Ding, “A modified stereographic projection approach and a free software tool for kinematic analysis of rock slope toppling failures," Bulletin of Engineering Geology and the Environment, vol. 78, no. 7, pp. 4757-4769, 2019. 
[19] R. L. MICHALOWSKI, "Stability of intact slopes with tensile strength cut-off," Geotechnique, vol. 67, no. 8, 8 pages, 2017.

[20] R. L. Michalowski and L. You, "Displacements of reinforced slopes subjected to seismic loads," Journal of Geotechnical and Geoenvironmental Engineering, vol. 126, no. 8, pp. 685-694, 2000.

[21] C. J. Chang, W. F. Chen, and J. T. P. Yao, "Seismic displacements in slopes by limit analysis," Journal of Geotechnical Engineering, vol. 110, no. 7, pp. 860-874, 1984.

[22] R. W. Jibson, E. L. Harp, and J. A. Michael, "A method for producing digital probabilistic seismic landslide hazard maps," Engineering Geology, vol. 58, no. 3-4, pp. 271-289, 2000.

[23] S. Utili and A. H. Abd, "On the stability of fissured slopes subject to seismic action," International Journal for Numerical and Analytical Methods in Geomechanics, vol. 40, no. 5, pp. 785-806, 2016. 